\title{
Unusual Craniocerebral Wounds by Penetrating Objects of Low Kinetic Energy: 3 Case Reports and a Review of Literature
}

Benantar $\mathrm{L}^{1^{*}}$, Assamadi $\mathrm{M}^{1}$, Ksiks $\mathrm{O}^{1}$, Ait $\mathrm{M}^{\prime}$ barek $\mathrm{Y}^{1}$, Aniba $\mathrm{K}^{1}$

${ }^{1}$ Neurosurgery Departement, Ibn Tofail Hospital, Mohamed VI University Hospital Center, Marrakesh, Morocco

DOI: $\underline{10.36347 / \text { simcr.2021.v09i03.028 }}$

| Received: 20.02.2021 | Accepted: 26.03.2021 | Published: 30.03 .2021

*Corresponding author: Benantar lamia

Abstract

Original Research Article

Introduction: Craniocerebral wounds are open head injuries that can lead the brain parenchyma to communicate with the external environment. Penetrating objects of low kinetic energy are a rare cause of this type of lesions. This article is a presentation of 3 case studies of head trauma by penetrating objects seen in the department of neurosurgery of Ibn Tofail Hospital, Mohamed VI University Hospital Center of Marrakesh. Results: We report the cases of 3 patients admitted with a penetrating head trauma (craniocerebral wounds): two by knife following an assault and one by a metal bar due to a work-related incident. Our patients were conscious with Glasgow coma scale (GCS) of $15 / 15$ in 2 patients and a score of $14 / 15$ in 1 patient. A CT-scan of the head and a skull X-ray were performed for all 3 patients. The therapeutic management included a medical and surgical component (craniectomy, reconstruction of the dura mater and the skin). The evolution was favorable in all 3 cases. Conclusion: Craniocerebral wounds by penetrating objects are rare, but remain frequent in third world countries. A GCS of 8 or less is an indicator of poor prognosis. Infections and seizures are the most common complications. Despite their often spectacular appearance, these traumas are not always life-threatening.

Keywords: Craniocerebral wounds, penetrating object, low kinetic energy.

Copyright $(\mathcal{C}) 2021$ The Author(s): This is an open-access article distributed under the terms of the Creative Commons Attribution 4.0 International License (CC BY-NC 4.0) which permits unrestricted use, distribution, and reproduction in any medium for non-commercial use provided the original author and source are credited.

\section{INTRODUCTION}

Craniocerebral wounds are head traumas; due to penetrating objects, causing a dural tear and putting the subarachnoid space in direct communication with the external environment. Low kinetic energy intracranial foreign bodies are a rare cause of brain damage. Many isolated cases have been reported in literature. We present the report of 3 cases of head traumas by penetrating objects that were admitted and treated at the neurosurgery department of Ibn Tofail Hospital of Mohamed VI University Hospital in Marrakech.

\section{Patients and Methods}

We report a series of three patients admitted at Ibn Tofail Hospital of Mohamed VI University Hospital Center in Marrakech for a penetrating head trauma with different mechanisms of injury.

\section{RESULTS}

Fist case: An 18 year old patient presenting with a stab wound to the head following an attack. On admission, the patient was confused with a GCS of 14/15. Physical exam shows a right hemiparesis associated with repeated episodes of vomiting. The patient underwent a skull $\mathrm{x}$-ray lateral view and a CTscan of the head, both showing an oblique downward penetrating head wound through the parietal lobe coming in contact with the left occipital lobe without any other associated lesions (Figure-1). 


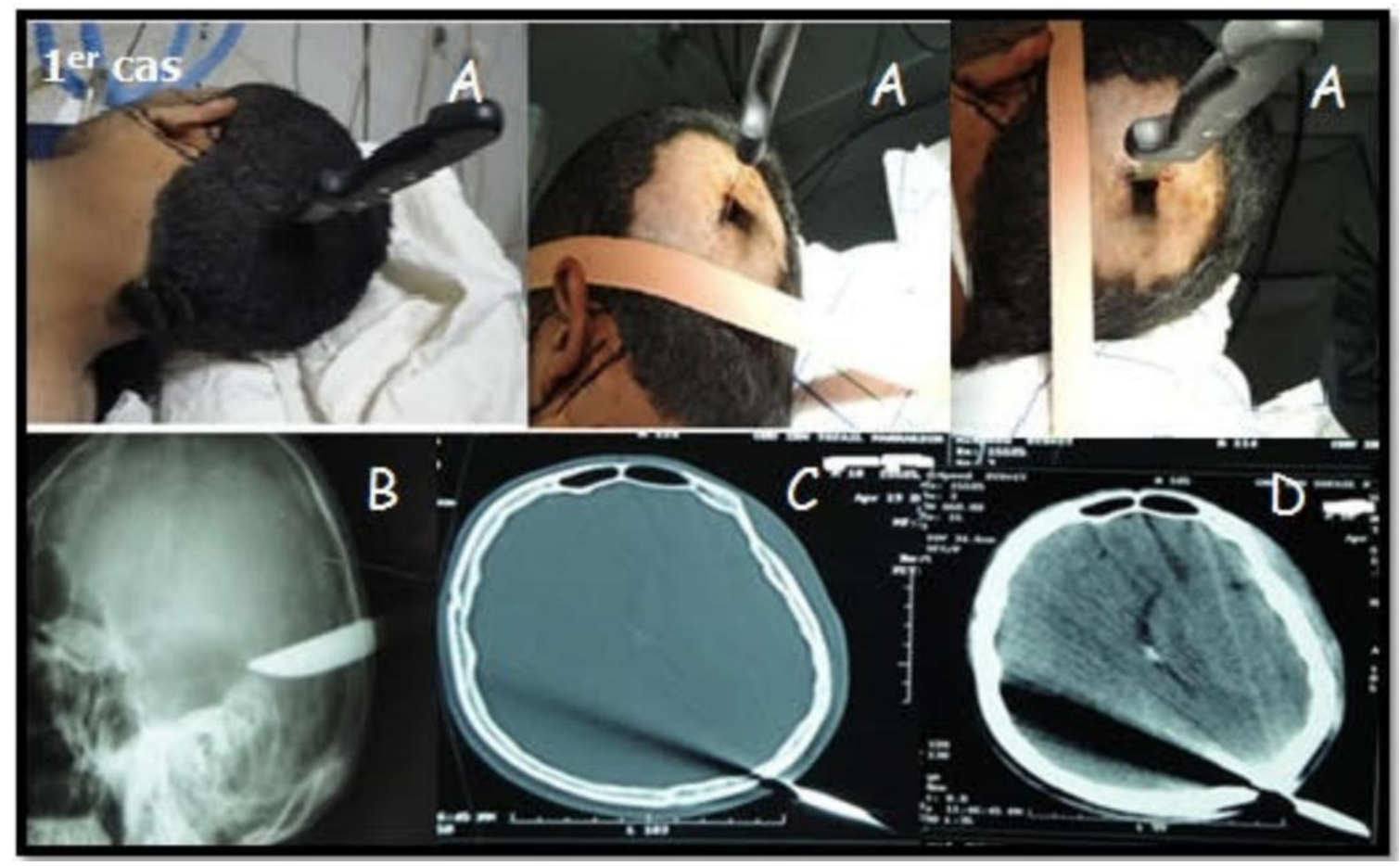

Fig-1: First case: Preoperative images (A) showing the nature of the traumatic object and its topography. Standard X-ray of the skull (B) specifying the path, depth and width of the object. Brain CT scan with bone window (C) and parenchymal window (D), highlighting artifact pathway of the traumatic agent, without associated parenchymal lesion

Second case: A 23-year-old patient, working in a construction site, suffered a work incident described as a blow to the head with a metal bar resulting in a penetrating head trauma. The patient was conscious with a GCS of $15 / 15$, presenting with severe headaches and vomiting. Physical exam did not find any neurological deficit. Radiological assessment with a skull x-ray lateral view showed the depth of the penetration. A complementary CT scan showed areas of contusions and pneumocephaly in the left parietal lobe around the bar (Figure-2).

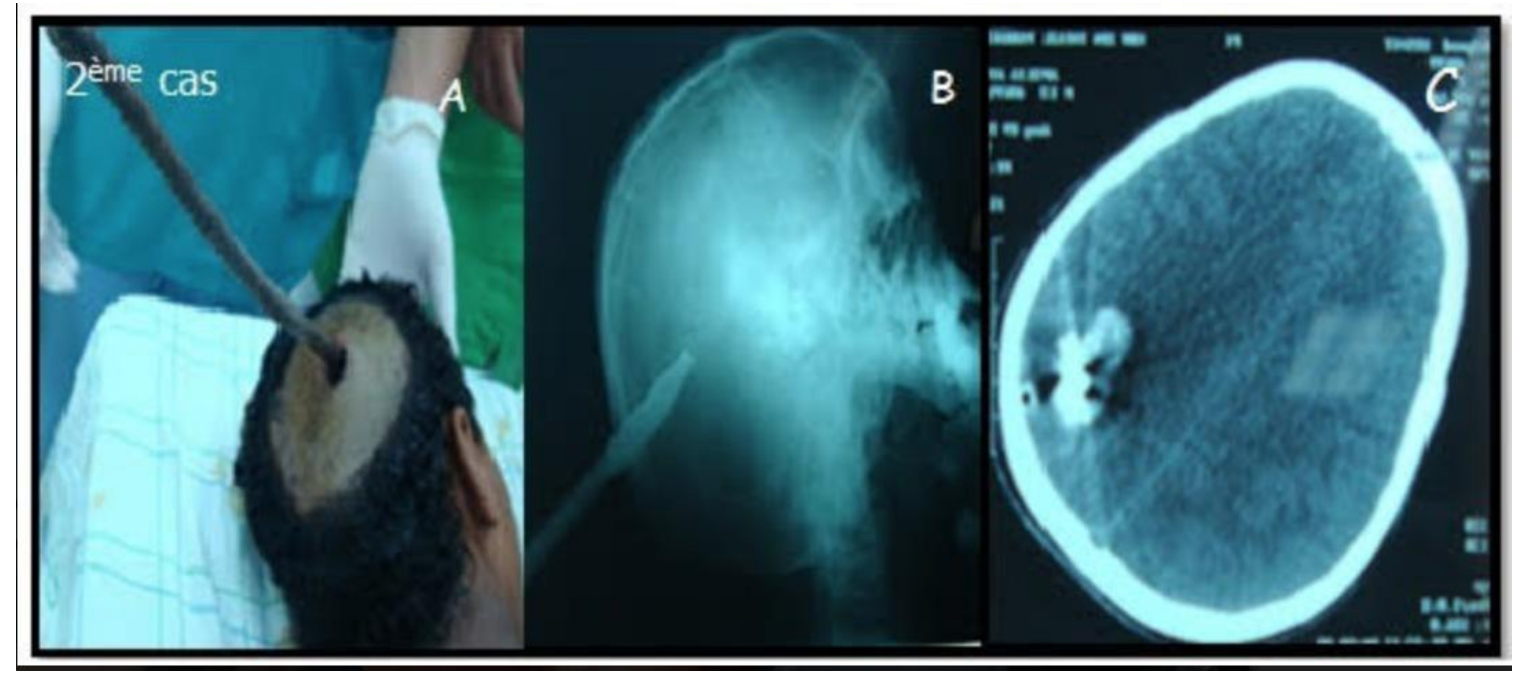

Fig-2: Second case: Preoperative image (A) of the 2nd patient showing a metal bar penetrating right parietal area. Standard radiography of the skull profile (B) shows the depth of penetration of the metal bar. Cerebral computed tomography (C) shows haemorrhagic contusion with left parietal pneumocephalus around the metal bar

Third case: A 26 year old patient suffered a stab wound to the left temporal region of the cranium following an assault. He was conscious on admission with a GCS of 15/15. Physical exam showed a localized bleeding without any neurological deficit. Skull X-rays anteroposterior (AP) and lateral views with a complementary CT scan showed a penetrating wound with a parallel trajectory to the mid-level of the base of the skull crossing the left temporal lobe with no other associated lesions (Figure-3). 


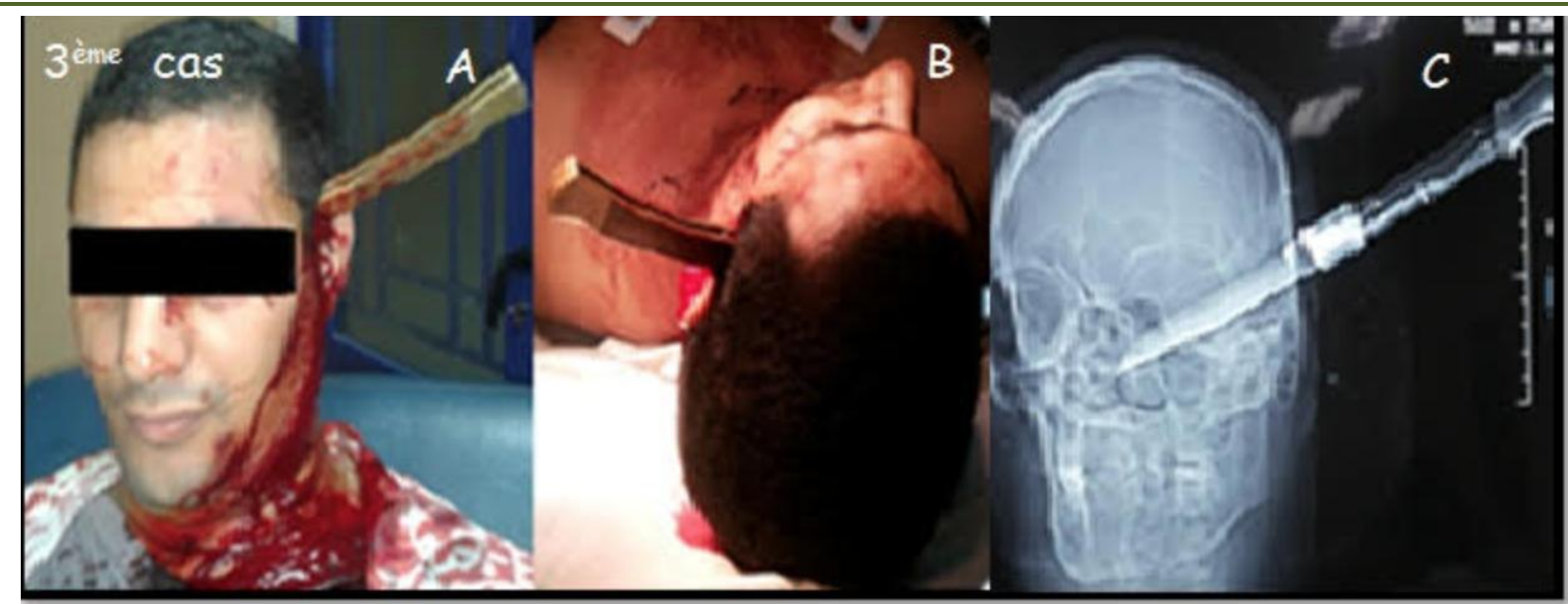

Fig-3: Third case : Image (A,B) assault by a white weapon in left temporal impact point. X-ray of skull face (C) shows the degree of penetration of the weapon

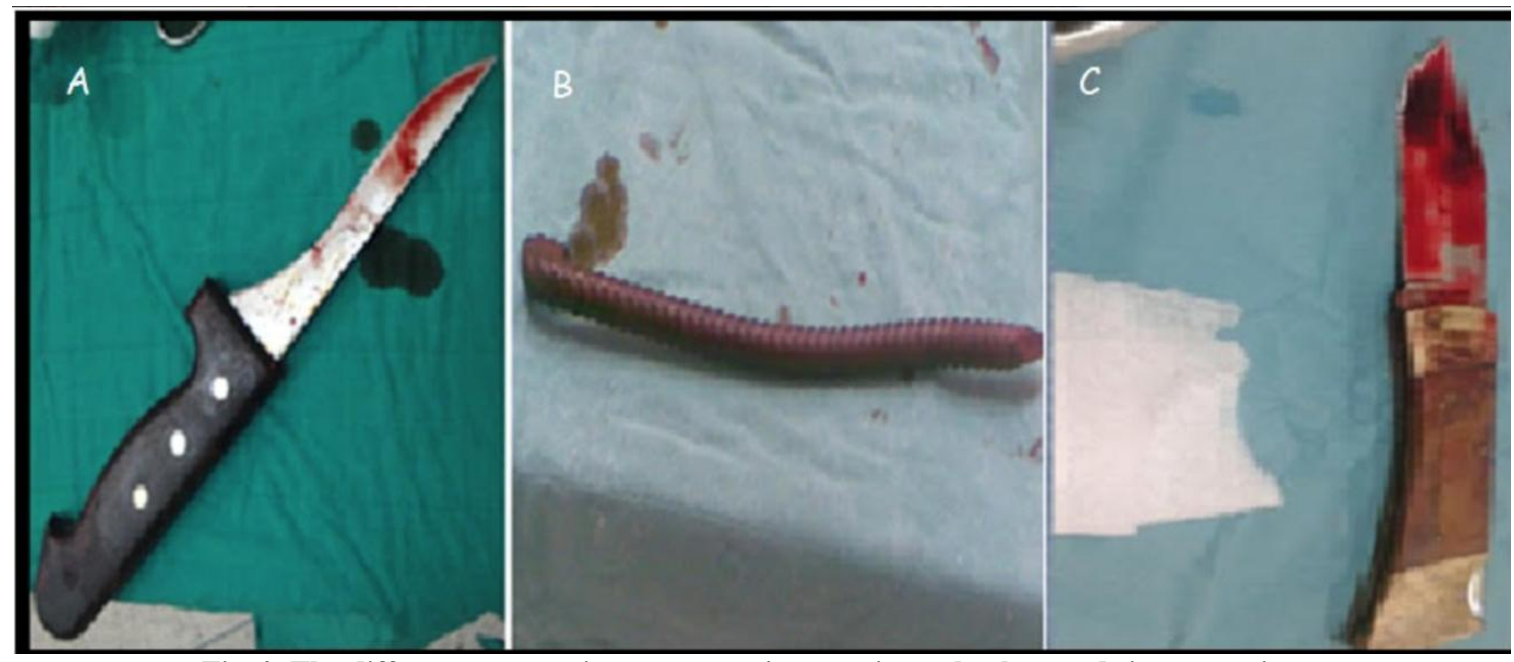

Fig-4: The different traumatic agents causing craniocerebral wounds in our patients

Therapeutic management was based on surgical treatment consisting on a limited craniectomy circumscribing the penetrating object with removal of the latter (Figure-4), associated with trimming and excision of the necrotic tissue and a plasty of the dura. Medical treatment consisted of antibiotic prophylaxis with amoxicillin-clavulanic acid, anticonvulsant treatment with sodium valproate, tetanus serotherapy and analgesic treatment adjusted to the intensity of the pain.

Evolution was favorable in all patients, with progressive recovery of the deficit after a month of rehabilitation for the first patient.

\section{DiscUSSION}

Cranioencephalic wounds by penetrating objects are unusual and represent 3 to $13.3 \%$ of the lesions found in head trauma patients all severity included [2, 3]. A male predominance was reported in all publications with a sex ratio between 4.33 and 6.76; this is explained by the high exposure of men to risk factors for head trauma (assault, work accidents, brawl, etc.) $[2,4]$.
The purpose of the initial clinical examination of head trauma patients was to determine the prognosis factors influencing therapeutic management. It includes the evaluation of respiratory and circulatory distress that must be corrected before assessing the neurological state [4].

The patients' initial GCS represents a major prognostic factor. As reported by several studies, an initially low GCS was associated with a high mortality rate [5].

A CT-scan of the head was systematically and urgently performed to determine the depth of penetration, the path of the object and the existence of any intraparenchymal lesions. However the analysis of CT-scans is often hampered by artefacts caused by metallic objects. This is why skull $\mathrm{x}$-rays; AP and lateral views, remain of interest in the radiological assessment of craniocerebral wounds. They allow a clear visualization of bone damage and a better analysis of the location of these foreign bodies [6]. 
Regarding therapeutic management, hemostasis always precedes neurosurgical treatment in order to stabilize the patients [7]. The treatment of these lesions should at best be carried out in two stages [6]:

- Emergency interventions: skin and subcutaneous cleaning and trimming, removal of foreign bodies and superficial bone fragments, watertight closure of the dura and scalp. Studies of recent series show that craniotomy performed for a meticulous removal of projectile fragments, significantly increases the morbidity and mortality of craniocerebral wounds $[6,7]$. In patients with intracranial hypertension, decompressive craniectomy is recommended for the management of severe craniocerebral wounds [8].

- Secondary interventions: following an emergency intervention, patients remain under clinical and CT-scan surveillance and might undergo an evacuation of any secondary hematomas, tight plasties of the dura mater and skin closure sometimes requiring rotational flaps. Repair of bone loss should only be considered several months after the trauma, if necessary [6].

Medical treatment is always prescribed, including resuscitation measures, the prevention of tetanus infection by antitetanus vaccination, and antibiotic prophylaxis targeting primarily staphylococcus by amoxicillin-Clavulanic acid. Antipneumococcal and anti-meningococcal vaccination is also performed $[4,1]$. The anti-seizure medications must be started as soon as possible for a period of 10 days despite the absence of seizures, given the high risk of their occurrence [2].

In craniocerebral wounds, the kinetic energy of the trauma is largely absorbed by the scalp and skull, limiting the diffusion of this energy into the cerebral parenchyma [2]. Nevertheless they are often associated with a heavy mortality rate, close to $30 \%$ in the military series. This mortality is mostly linked to a neurological cause or a hemorrhagic shock. The main complications encountered are central nervous system infections $10 \%$ (Meningitis, abscess and empyema), leakage of cerebrospinal fluid (CSF) $5-10 \%$, early or delayed onset epilepsy $10-15 \%$ and vascular complications $25-30 \%$ (Aneurysms and vasospasm) [9].

As a result of early management, evolution of neurosurgical treatments, imaging techniques and the availability of large-spectrum antibiotics, the mortality of craniocerebral wounds has reached significantly lower rates but it remains unsatisfying, hence the focus of primary prevention.

\section{CONCLUSION}

Craniocerebral wounds by penetrating objects are uncommon, but remain frequent in third world countries. A GCS of 8 or less is an indicator of poor prognosis. Infections and seizures are the most common complications. Despite their often spectacular appearance, these traumas are not always lifethreatening.

\section{REFERENCE}

1. Daban J, Delmas J, Dulou R, Debien B. Plaies craniocérébrales: de l'hôpital en Afghanistan à la prise en charge en France. Urgence, 2012; chapitre 81.

2. Diop AA, Tine I, et Hode L. les plaies cranioencephaliques: Aspects epidemic-Cliniques et Therapeutiques a Dakar (Senegal). African Journal of Neurological Sciences. 2011; 30(1).

3. Hode L. Prise en charge des traumatismes crânioencéphaliques chez les enfants à Cotonou. Neurochirurgie. 2014; 60(6):336.

4. Rasolonjatovo E, Tsiaremby M, Rakotondraibe W, Ratovondrainy W, Rabarijaona M, Andriamamonjy C. Prise en charge des plaies cranio-cérébrales au CHU Joseph Ravoahangy Andrianavalona, Antananarivo-Madagascar. Rev. Anesth.-Réanim. Med. Urg. Toxicol. 2016 JuilletDécembre; 8(2):4-7.

5. Bahloul M, Hamida CB, Chelly H, Chaari A, Kallel H, Dammak H, ... Bouaziz M. Severe head injury among children: prognostic factors and outcome. Injury. 2009; 40(5): 535-40.

6. Aesch B, Jan M. Traumatismes crânioencéphaliques. Encycl Méd Chir 17-585-A-10

7. Daban JL, Peigne V, Boddaert G, Ondo RO, Paul S, Debien B. Traumatisme pénétrant et balistique. Conférences d'actualisation. Congrès national d'anesthésie et de réanimation. 2012, Paris.

8. Ecker RD, Mulligan LP, Dirks M, Bell RS, Severson MA, Howard RS, Armonda RA. Outcomes of 33 patients from the wars in Iraq and Afghanistan undergoing bilateral or bicompartmental craniectomy. J Neurosurg. 2011;115(1), 124

9. Bell RS, Vo AH, Neal CJ, Tigno J, Roberts R, Mossop C, Dunne JR, Armonda RA. Military traumatic brain and spinal column injury: a 5-year study of the impact blast and other military grade weaponry on the central nervous system. J Trauma. 2009; 66(4): S104-111. 